\title{
Masked Alkyne Equivalents for the Synthesis of Mechanically Interlocked Polyynes
}

\author{
Przemyslaw Gawel, Steffen L. Woltering, Yaoyao Xiong, Kirsten E. Christensen, and Harry L. \\ Anderson*
}

Dedicated in memory of François Diederich (1952-2020)

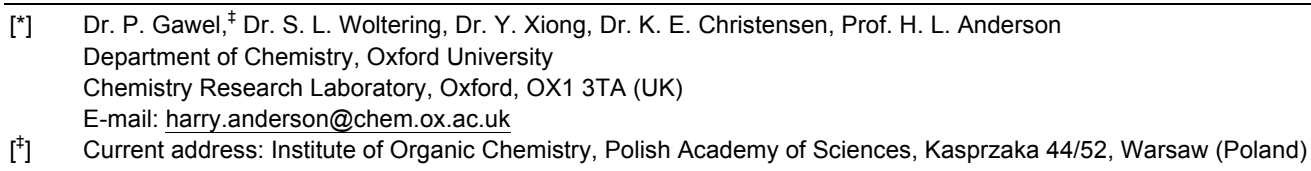

Supporting information for this article is given via a link at the end of the document.

\begin{abstract}
Polyyne polyrotaxanes, encapsulated cyclocarbon catenanes and other fascinating mechanically interlocked carbonrich architectures should become accessible if masked alkyne equivalents (MAEs) can be developed that are large enough to prevent unthreading of a macrocycle, and that can be cleanly unmasked under mild conditions. Here we report the synthesis of a new bulky MAE based on a $t$-butylbicyclo[4.3.1]decatriene. This MAE was used to synthesize a polyyne [2]rotaxane and a maskedpolyyne [3]rotaxane by Cadiot-Chodkiewicz coupling. Glaser cyclooligomerization of the [2]rotaxane gave masked cyclocarbon catenanes. The unmasking behavior of the catenanes and rotaxanes was tested by photolysis at a range of UV wavelengths. Photochemical unmasking did not proceed cleanly enough to prepare extended encapsulated polyyne polyrotaxanes. We highlight the scope and challenges involved with this approach to interlocked carbon-rich architectures.
\end{abstract}

\section{Introduction}

The synthesis of polyynes has attracted attention ever since the invention of the Glaser and Cadiot-Chodkiewicz coupling reactions. ${ }^{[1]}$ Polyynes are models for the elusive carbon allotrope carbyne ${ }^{[2]}$ which consists of infinite linear chains of $s p$ hybridized carbon atoms. The extreme electronic and mechanical properties predicted for this material have inspired generations of experimentalists and theorists, ${ }^{[3]}$ but its synthesis is precluded by its high reactivity and by the tendency of long polyyne chains to undergo exothermic crosslinking reactions. ${ }^{[4]}$ Bulky end groups have been shown to stabilize carbon chains of up to 48 atoms. ${ }^{[5,6]}$ Other strategies for stabilizing carbon chains include rotaxane formation ${ }^{[7-9]}$ and helical wrapping. ${ }^{[10]}$ Extreme stabilization has been achieved by encapsulation inside carbon nanotubes, but this strongly modulates the properties of the $1 \mathrm{D}$ carbon chain. ${ }^{[11]}$

Polyrotaxane formation is an appealing approach to stabilizing polyynes because the macrocyclic components could cover the whole length of the carbon chain, shielding regions that are unaffected by bulky end groups; in principle, this strategy could stabilize polyynes of any length. Synthetic approaches to polyyne [2]rotaxanes are well developed, ${ }^{[7,8]}$ particularly using active metal templates, ${ }^{[12,13]}$ but there is a need for effective methods for threading many macrocycles onto a long polyyne thread to form a polyrotaxane.

Masked alkyne equivalents (MAEs) have been used since the 1980s to release polyyne chains from suitable precursors. Unmasking is achieved using light, ${ }^{[14-16]}$ heat, ${ }^{[17]}$ chemical reagents ${ }^{[18-21]}$ and on-surface using voltage pulses. ${ }^{[22,23]}$ MAEs have opened synthetic avenues to cyclocarbons, rings consisting entirely of $s p$-hybridized carbon atoms. ${ }^{[17-19,23]}$ While cyclocarbons were successfully studied on surfaces using $\mathrm{AFM},{ }^{[23]}$ they are only stable at low temperatures. One strategy for making them stable under ambient conditions may be to encapsulate them by catenane formation, ${ }^{[24]}$ by analogy with the stabilization of cyclobutadiene inside a hemicarcerand, demonstrated by Cram and co-workers. ${ }^{[25]}$ The synthesis of cyclocarbon catenanes could be achieved using MAEs that act as stoppers in a rotaxane intermediate. Such a rotaxane would be a versatile building block for encapsulated cyclocarbons and carbyne polyrotaxanes, as a form of insulated molecular wire. ${ }^{[26]}$

Most reported MAEs are too small to act as stoppers in rotaxanes. Here we explore a MAE based on the bicyclo[4.3.1]decatriene pioneered by Tobe, ${ }^{[15]}$ but with a $t$-butyl group in the periphery of the indane ring to increase the steric bulk. When irradiated with UV light, bicyclo[4.3.1]decatrienes 1 generate a carbene, via a cheletropic ring opening, which rearranges rapidly to form an alkyne 2 (Scheme 1). ${ }^{[15]}$ Here we demonstrate that this masking group is large enough to prevent slipping of a small phenanthroline macrocycle $3^{[27]}$ by synthesizing rotaxane 4 (Scheme 2). We also demonstrate that this MAE can be used to synthesize masked polyyne polyrotaxanes and masked cyclocarbon catenanes, and we test the photochemical unmasking of these compounds.

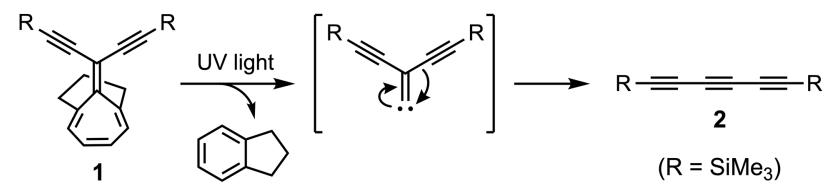

Scheme 1. Photochemical unmasking of bicyclo[4.3.1]decatriene 1 and subsequent rearrangement of the carbene to form TMS-triyne $2 .^{[15]}$ 




3
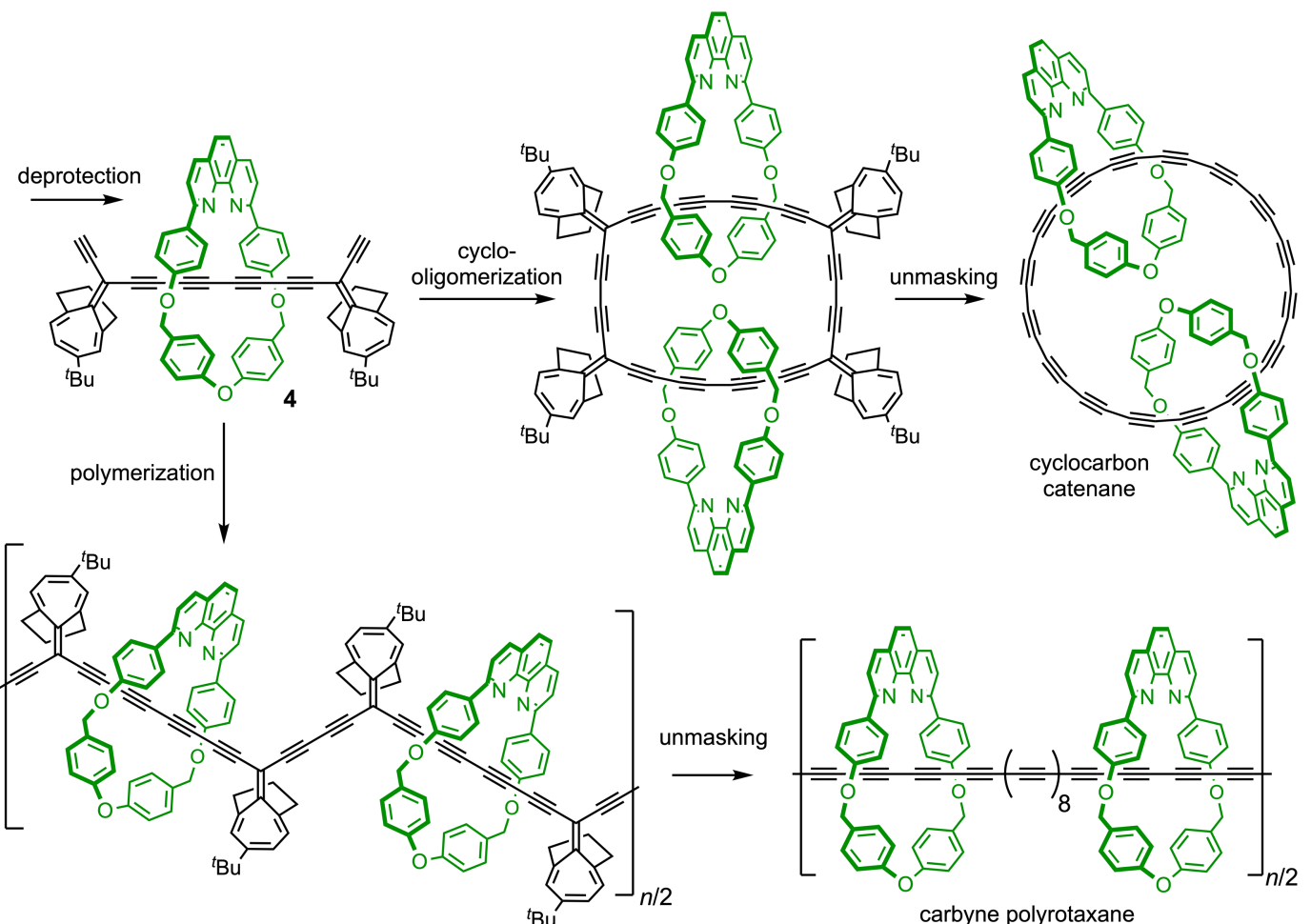

Scheme 2. Proposed synthetic route to cyclocarbon catenanes and carbyne polyrotaxanes. (PG = protecting group.)

\section{Results and Discussion}

\section{1. [2]Rotaxane Synthesis}

Designing a bulky photocleavable MAE was the first challenge in this project. The most promising photocleavable MAE was identified as Tobe's bicyclo[4.3.1]decatriene. In contrast to the other photocleavable MAE developed by Tobe's group ([4.3.2]propellatriene), ${ }^{[14]}$ it is not fused as an annulated ring but attached to a double bond that is cross-conjugated with the acetylene network; as a result, it protrudes further from the polyyne chain, increasing the steric bulk. However, model studies using polyynes masked with unsubstituted bicyclo[4.3.1]decatriene and macrocycle 3 did not yield rotaxanes, indicating that the macrocycle can slip over this MAE. This problem was solved by adding a $t$-butyl group.

Masked triyne 13 is synthesized as shown in Scheme 3. Indane is alkylated selectively under Friedel-Crafts conditions to give 5. ${ }^{[28]}$ Subsequent Birch reduction yields cyclohexadiene 6 . Dibromocarbene attacks 6 predominantly on the central double bond to yield 7 , whereas in absence of the $t$-butyl group both double bonds react, ${ }^{[29]}$ reflecting a change in reactivity caused by the additional bulk of the $t$-butyl group. Reaction conditions for addition of bromine to 7 to give tetrabromide 8 had to be carefully optimized, because Tobe's procedure (using pyridinium tribromide ${ }^{[15]}$ gave an overbrominated product $\mathbf{S 1}$ (which was unambiguously identified by a single-crystal $\mathrm{X}$-ray analysis; see Supporting Information S7). Use of elemental bromine in carbon tetrachloride at $0{ }^{\circ} \mathrm{C}$ gave the desired tetrabromide 8 , which was immediately submitted for elimination using DBU to furnish $\mathbf{9}$ in $40 \%$ yield over two steps. Intermediate 9 can be prepared in large quantities and stored indefinitely without special precautions, and its structure was confirmed by X-ray crystallography (see Supporting Information S7).

When 9 is treated with $t-\mathrm{BuLi}$, one of the bromines is exchanged for lithium and the carbanion can be captured with ketone $1^{[30]}$ to install alkyne units in the periphery of the MAE, to give 11, after quenching with TMS-chloride. Another lithiumbromine exchange with $t$-BuLi eliminates the O-TMS group to give masked triyne 12. Interestingly, this elimination is accompanied by a skeletal rearrangement: the [4.3.1]propellane undergoes an electrocyclic reaction to form the bicyclo[4.3.1]decane, as revealed by the fact that the bridgehead carbon signal is shifted from $47 \mathrm{ppm}$ in 11 to $140 \mathrm{ppm}$ in 12 . This is in accord with previous reports ${ }^{[15,31]}$ and the rearrangement is probably driven by the strain in the cyclopropane subunit with an exocyclic double bond. 


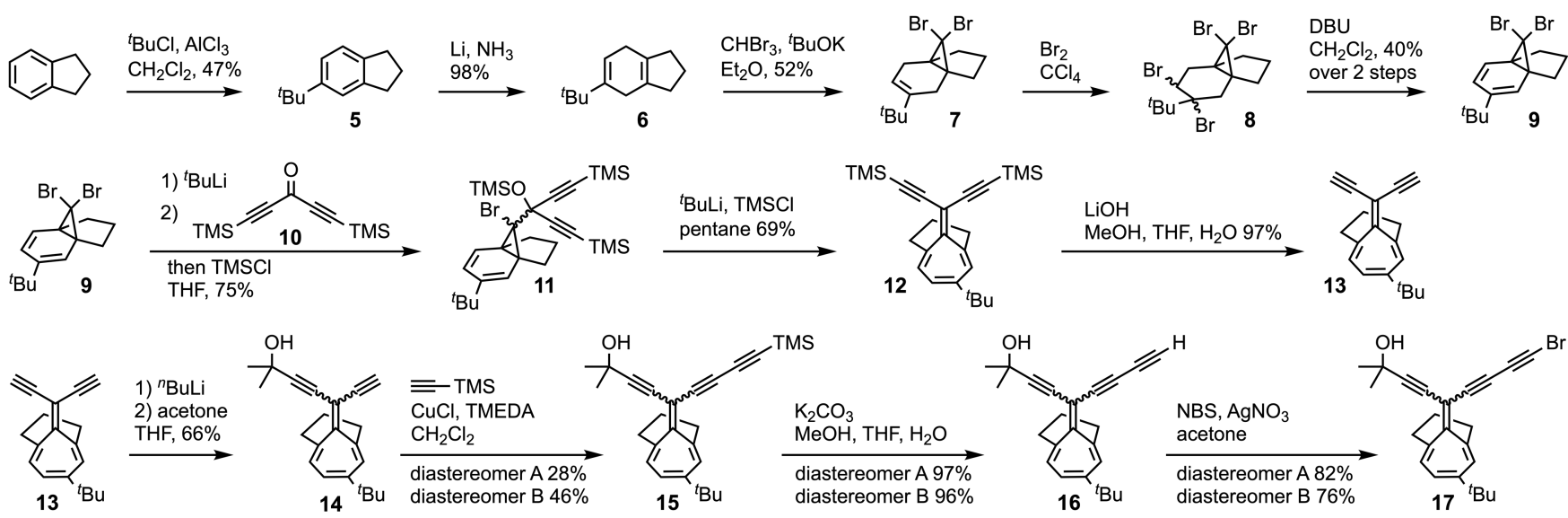

Scheme 3. Synthesis of bulky masked alkyne equivalent building blocks 16 and 17.

The TMS-alkynes are deprotected using aqueous $\mathrm{LiOH}$ to yield masked triyne 13, which can be desymmetrized by statistically protecting one of the terminal acetylenes as the acetone adduct, to give 14. The two alkynes in 13 are nonequivalent, due to the presence of the $t$-Bu substituent, and this protection reaction gives an inseparable mixture of the $E$ and $Z$ stereoisomers of $\mathbf{1 4}$ in a ratio of 2:3. It was not possible to assign the stereoisomers, as the distance between $t$-butyl group and terminal acetylene or acetonate group is too far to observe NOEs by ${ }^{1} \mathrm{H}$ NMR spectroscopy and all attempts to crystallize these compounds were unsuccessful. Glaser coupling with TMS-acetylene yields the masked tetrayne $\mathbf{1 5}$ and separation of the $E$ and $Z$ stereoisomers was achieved at this stage, although it was still not possible to assign the isomers. The TMS group of 15 is removed by treatment with aqueous potassium carbonate to give the terminal acetylene 16, which is converted to the corresponding bromide 17 with NBS in the presence of $\mathrm{AgNO}_{3}$. Both 16 and 17 are unstable and quickly decompose (even at low temperature) in pure form. Therefore, these compounds were prepared immediately before use.

With compounds 16 and 17 in hands, we started screening conditions for [2]rotaxane formation. Homocoupling of alkyne 16 in the presence of macrocycle 3 , mediated by $\mathrm{Cu}(\mathrm{I})^{[12]}$ gave traces of interlocked product that could be detected by mass spectrometry, but the reaction was not sufficiently efficient to allow isolation of the rotaxane. In contrast, Cadiot-Chodkiewicz coupling between the terminal alkyne 16 and the bromide 17 gives [2]rotaxane 18 in 22\% yield (Scheme 4). Subsequent deprotection of the acetone groups with $\mathrm{K}_{2} \mathrm{CO}_{3} / 18-$ crown- $6^{[32]}$ gives the deprotected [2]rotaxane 4 in $60 \%$ yield. This [2]rotaxane is the first example of an interlocked compound in which a masked alkyne acts as a stopper. The interlocked character is unambiguously confirmed by ESI-MS and ${ }^{1} \mathrm{H}$ NMR spectroscopy. In some cases of active metal template rotaxane synthesis, use of a small tightly fitting macrocycle can enhance the yield of rotaxane ${ }^{[33]}$ but the synthesis of $\mathbf{1 8}$ is less efficient than similar reactions using larger macrocycles. ${ }^{[7,8]}$



Scheme 4. Cadiot-Chodkiewicz coupling of 16 and 17 in the cavity of 3 yields [2]rotaxane 18, which is deprotected with $\mathrm{K}_{2} \mathrm{CO}_{3}$ to give 4 .

The ${ }^{1} \mathrm{H}$ NMR spectrum of [2]rotaxane 4 is compared with the spectra of free macrocycle 3 and free thread 19 in Figure 1. As the axle is formed as a mixture of diastereomers, additional splittings for the macrocycle peaks are observed. The macrocycle also affects the peaks of the axle and increases the splitting between the $E$ and $Z$ isomers; for example, the signal for the proton of the terminal acetylene ( $d$ in Figure 1) appears as a singlet in free thread 19, but it is split in [2]rotaxane 4 . The effect of interlocking is stronger for proton a (shielded by $0.2 \mathrm{ppm}$ in the [2]rotaxane) of the cycloheptatriene ring compared to signals $\mathrm{b}$ and $\mathrm{c}$, which are almost unaffected by the presence of the threaded macrocycle. [2]Rotaxanes such as 4 hold great potential as building blocks for numerous systems involving encapsulated alkynes. To demonstrate this, we show how interlocked systems of higher order can be derived from this subunit of a masked encapsulated polyyne. 




Figure 1. ${ }^{1} \mathrm{H}$ NMR spectra $\left(\mathrm{CDCl}_{3}, 298 \mathrm{~K}, 400 \mathrm{MHz}\right)$ of macrocyle 3, rotaxane 4 and free thread 19 . The signals of the macrocycle are strongly split because the thread is synthesized as a mixture of diastereomers.

\section{2. [3]Rotaxane Synthesis}

The synthesis of a [3] rotaxane was investigated as a step towards the preparation of longer carbyne polyrotaxanes. An asymmetric [2] rotaxane $\mathbf{2 1}$, with the MAE stopper on one side and a bulky supertrityl stopper on the other side, was synthesized via a Cadiot-Chodkiewicz coupling between bromo alkyne 17 and supertrityl triyne $\mathbf{2 0}^{[5]}$ in the presence of macrocycle 3 (Scheme 5). In an attempt to keep the NMR spectra simple, pure samples of diastereomer A of 16 (unknown $E$ or $Z$ stereochemistry) was used in this line of experiments. The bulky supertrityl stoppers were chosen to ensure that the interlocking of components is maintained after unmasking of the MAE. Removal of the acetonide protecting group with $\mathrm{K}_{2} \mathrm{CO}_{3}$ and 18-crown-6 yielded 22. Oxidative Glaser homo-coupling of $\mathbf{2 2}$ gives [3]rotaxane $\mathbf{2 3}$ in $51 \%$ yield. The structure of $\mathbf{2 3}$ was unambiguously confirmed by NMR spectroscopy and mass spectrometry. At this stage, the [3]rotaxane is compartmentalized: the macrocycles are trapped between the supertrityl stopper unit and the MAE and cannot shuttle freely along the polyyne thread. These findings indicate that it is generally possible to synthesize masked, encapsulated polyyne chains using this approach, which opens synthetic avenues towards the synthesis of encapsulated carbyne (Scheme 1).

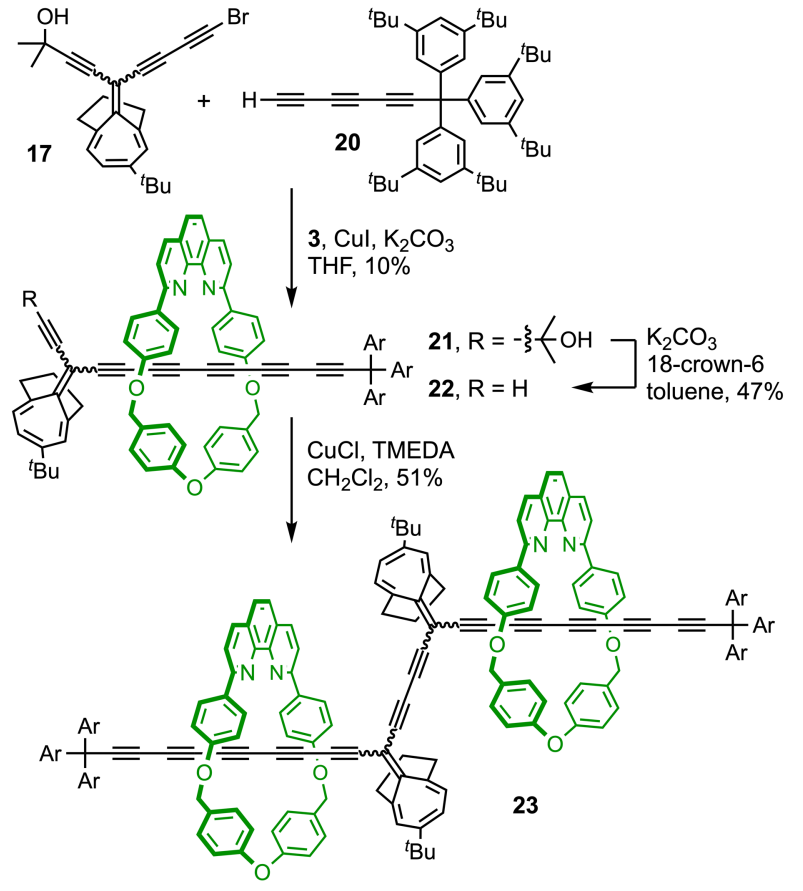

Scheme 5. Synthesis of [3]rotaxane 23.

\section{Synthesis of Masked Cyclocarbon Catenanes}

Catenanes were prepared from [2]rotaxane 4 (consisting exclusively of diastereomer B) by Glaser cyclo-oligomerization under dilute conditions. A range of conditions was screened, and 
only coupling with copper $(\mathrm{I})$ chloride in pyridine under oxygen yielded catenanes (Scheme 6). [3]Catenane 24 and [4]catenane 25 were separated by recycling gel permeation chromatography and isolated in $5 \%$ and $4 \%$ yield, respectively. The constitution of $\mathbf{2 4}$ and $\mathbf{2 5}$ was demonstrated by MALDI mass spectrometry, demonstrating that cyclization of rotaxane building blocks is a viable route to masked cyclocarbon catenanes. Unfortunately, we were unable to record informative NMR spectra of these catenanes; they gave broad and poorly resolved spectra, which probably reflects the fact that they are complex mixtures of diastereomers. (Even using a single diastereomer of $\mathbf{4}$ is expected to give 7 stereoisomers of $\mathbf{2 4}$ and 24 stereoisomers for $\mathbf{2 5}$ ).

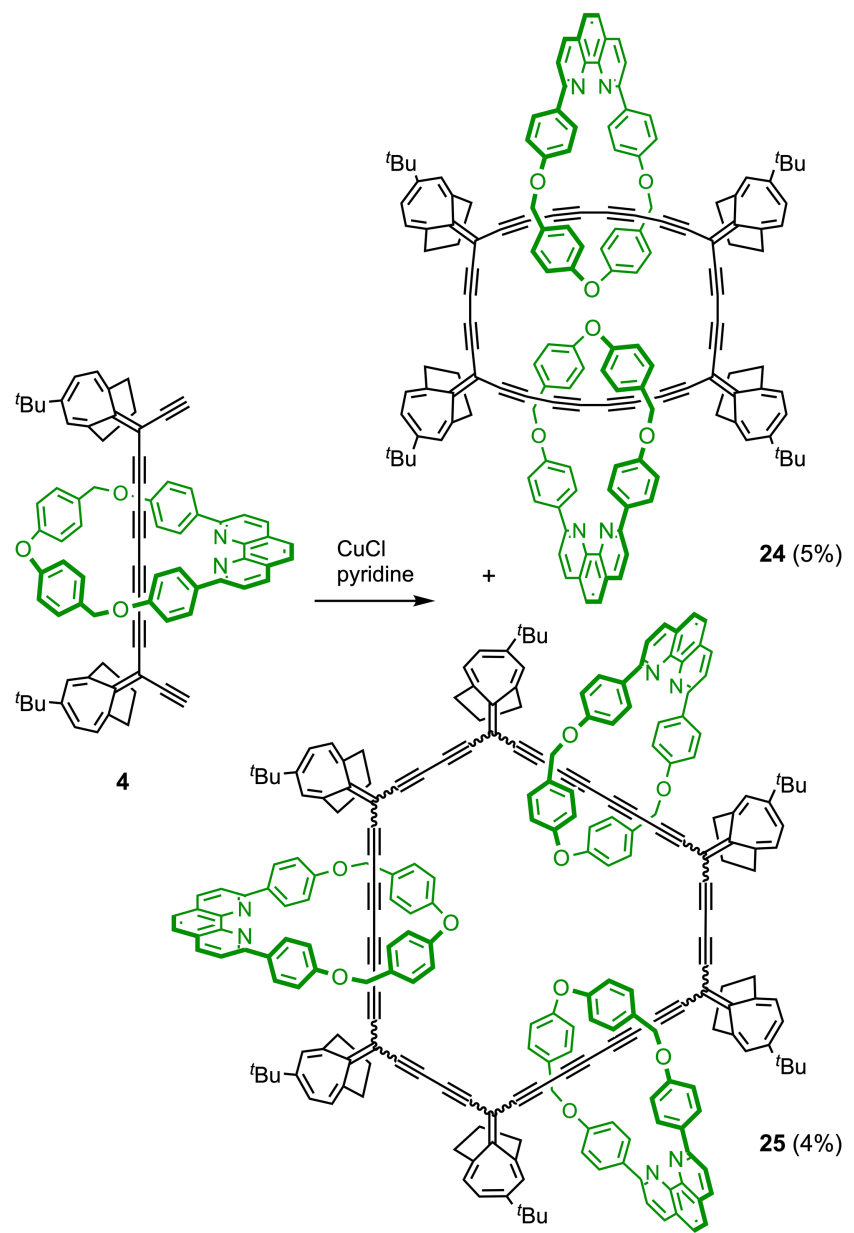

Scheme 6. Synthesis of masked cyclocarbon catenanes 24 and 25 via copper-mediated cyclo-oligomerization of rotaxane 4 .

\section{Photochemical Unmasking}

Tobe reported photochemical unmasking of compound 1 to give triyne 2 in $43 \%$ yield (Scheme 1), ${ }^{[15]}$ so we decided to investigate whether the additional $t$-butyl group in the present system influences its photochemical reactivity. TMS-protected MAE 12 was chosen as an appropriate model to study the photochemistry of this system.

The ${ }^{1} \mathrm{H}$ NMR spectra of compound 12 before and after irradiation at $250 \mathrm{~nm}$ in $\mathrm{CDCl}_{3}$ are compared in Figure 2. Under the conditions of our experiment, unmasking was complete after $4 \mathrm{~h}$ of irradiation. The unmasking reaction appears to proceed cleanly to the corresponding TMS-triyne $\mathbf{2}$ and $t$-butyl indane $\mathbf{5}$, but decomposition via an unknown pathway takes place and the signal-to-noise-ratio decreases over time. This contrasts with the photochemistry of unsubstituted $\mathbf{1}$, in which an isomerized product is formed in $30 \%$ yield via a 1,5 -sigmatropic shift. ${ }^{[34]}$

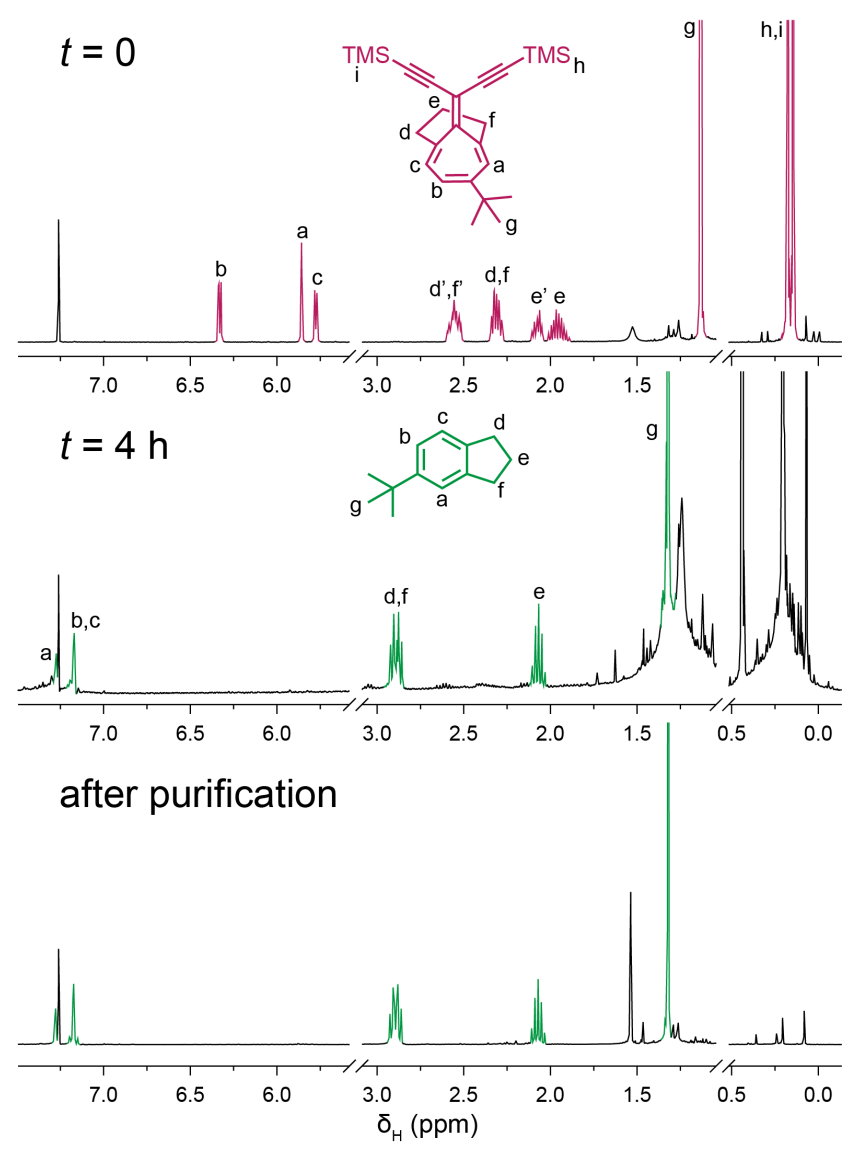

Figure 2. ${ }^{1} \mathrm{H}$ NMR spectra $\left(\mathrm{CDCl}_{3}, 298 \mathrm{~K}, 400 \mathrm{MHz}\right)$ of UV unmasking $(250 \mathrm{~nm})$ of 9 in $\mathrm{CDCl}_{3}$.

Using adamantane as an internal ${ }^{1} \mathrm{H}$ NMR standard, the yield for $\mathbf{5}$ and $\mathbf{2}$ from irradiation of $\mathbf{1 2}$ was determined to be $37 \%$ and $47 \%$, respectively (with an experimental uncertainty of about $3 \%)$, which is consistent with the isolated yields $(23 \% \mathbf{5}$, $36 \% 2$ ). The unmasking performance could not be improved by switching to longer wavelengths $(300 \mathrm{~nm}, 350 \mathrm{~nm})$ or by varying concentration, or changing the solvent to cyclohexane. Unfortunately, the photochemical performance of this particular MAE is not suitable for the unmasking of extended systems with multiple MAE units, because the yield is expected to drop exponentially with the number of masking units present in the molecule. In spite of this, we tested the unmasking of [3]rotaxane 23, [3]catenane 24 and [4]catenane 25. In the case of [3] rotaxane 23, experimental evidence for unmasking was observed on irradiation at $250 \mathrm{~nm}$ (Scheme 7), Mass spectometric analysis of the reaction mixture showed strong peaks for the partially unmasked [3]rotaxane $\mathbf{2 6}$ and weak signals for fully unmasked [3]rotaxane 27. UV-vis analysis of the reaction mixture confirmed that unmasking was achieved, and 




Scheme 7. Photochemical unmasking of [3]rotaxane 23. When irradiated with UV light $(250 \mathrm{~nm})$ partially unmasked rotaxane $\mathbf{2 6}$ can be identified in the reaction mixture by ESI-MS. The UV-vis of the reaction mixture shows signature peaks for a supertrityl-stoppered tetradecayne, suggesting the formation of 27. Unmasking was not efficient enough to isolate $\mathbf{2 6}$ or the fully unmasked [3]rotaxane $\mathbf{2 7 .}$

the characteristic signature peaks of a tetradecayne stoppered by supertrityl groups were observed at 428,394 , and $378 \mathrm{~nm}$ (see Supporting Information S6), ${ }^{[5]}$ but the unmasked rotaxanes 26 and 27 were not isolated.

These findings suggest that unmasking of the catenanes 24 and 25 is unlikely to be viable using this particular MAE. Irradiation of $\mathbf{2 4}$ and $\mathbf{2 5}$ with UV light $(254 \mathrm{~nm})$ in either $\mathrm{CDCl}_{3}$ (at $20{ }^{\circ} \mathrm{C}$ ) or $n$-hexane (at $-80{ }^{\circ} \mathrm{C}$ ) was monitored by mass spectrometry, but no peaks for fully or partially unmasked cyclocarbon catenanes were observed. Based on the performance of the model compound, the theoretical yield for complete unmasking would be $4-6 \%$ for the [3]catenane and up to $1.5 \%$ for the [4]catenane.

\section{Conclusion}

We have demonstrated the first synthesis of a [2]rotaxane in which both stoppers are MAEs. Rotaxanes of this type are potential precursors of polyyne polyrotaxanes and cyclocarbon catenanes. The reactivity of this MAE (as tested in compounds $12,23,24$ and 25) is unsuitable for the preparation of interlocked polyynes, and highlights the need for better understanding of the structure-property relationships controlling the efficiency of photochemical unmasking. Recently, we showed that a different MAE based on indane is capable of unmasking within rotaxanes but is too small as a stopper. ${ }^{[8]}$ When modified appropriately to increase the steric bulk, such a system might unmask more efficiently than the MAE presented here. An alternative to photochemically activated systems might be the use of metal complexes as stoppering groups as they are inherently sterically demanding. ${ }^{[21]}$

\section{Acknowledgements}

We thank Daniel R. Kohn and Alexandru Vlasceanu for helpful discussions, and F. Wieland Goetzke and Maria A. Gafitescu for help with photoreactors. This project was funded by Leverhulme Trust project grant RPG-2017-032. P.G. was supported by Swiss National Science Foundation Postdoc.Mobility fellowship P300P2-177829. The authors acknowledge use of the University of Oxford Advanced Research Computing (ARC) facility http://dx.doi.org/10.5281/zenodo.22558.

Keywords: polyynes $\cdot$ rotaxanes $\cdot$ masked alkyne $\bullet$ supramolecular encapsulation $\cdot$ photochemistry

[1] (a) C. Glaser, Ber. Dtsch. Chem. Ges. 1869, 2, 422-424; b) W. Chodkiewicz, P. Cadiot, Hebd. Seances Acad. Sci. 1955, 241, 10551057; c) P. Siemen, R. C. Livingston, F. Diederich, Angew. Chem. Int. Ed. 2000, 39, 2632-2637; Angew. Chem. 2000, 112, 2740-2767.

[2] a) F. Diederich Nature 1994, 369, 199-207; b) W. A. Chalifoux, R. R. Tykwinski, C. R. Chim. 2009, 12, 341-358; c) R. R. Tykwinski, Chem. Rec. 2015, 15, 1060-1074; d) C. S. Casari, M. Tommasini, R. R. Tykwinski, Nanoscale 2016, 8, 4414-4435; e) C. S. Casari, A. Milani, MRS Commun. 2018, 8, 207-219.

[3] a) M. Kertesz, J. Koller, A. Azman, J. Chem. Phys. 1978, 68, 27792782; b) S. Tongay, R. T. Senger, S. Dag, S. Ciraci, Phys. Rev. Lett. 2004, 93, 136404; c) S. Yang, M. Miklos Kertesz, J. Phys. Chem. A 2006, 110, 9771-9774; d) Z. Zanolli, G. Onida, J.-C. Charlier, ACS Nano 2010, 4, 5174-5180; e) M. Liu, V. I. Artyukhov, H. Lee, F. Xu, B. I. Yakobson, ACS Nano 2013, 7, 10075-10082.

[4] a) P. Tarakeshwar, P. R. Buseck, H. W. Kroto, J. Phys. Chem. Lett. 2016, 7, 1675-1681; b) T. R. Hoye, B. Baire, D. Niu, P. H. Willoughby, B. P. Woods, Nature 2012, 490, 208-211; c) S. Schrettl, C. Stefaniu, C. Schwieger, G. Pasche, E. Oveisi, Y. Fontana, A. Fontcuberta i Morral, J. Reguera, R. Petraglia, C. Corminboeuf, G. Brezesinski, H. Frauenrath, Nat. Chem. 2014, 6, 468-467; d) E. T. Chernick, R. R. Tykwinski, J. Phys. Org. Chem. 2013, 26, 742-749.

[5] a) Y. Gao, Y. Hou, F. Gordillo-Gámez, M. Ferguson, J. Casado, R. R. Tykwinski, Nat. Chem. 2020, 12, DOI: 10.1038/s41557-020-0550-0; b) W. Chalifoux, R. R. Tykwinski, Nat. Chem. 2010, 2, 967-9714.

[6] a) B. Pigulski, N. Gulia, S. Szafert, Eur. J. Org. Chem. 2019, 14201445; b) M. Jevic, M. B. Nielsen, Asian J. Org. Chem. 2015, 4, 286-295.

[7] a) L. D. Movsisyan, M. Franz, F. Hampel, A. L. Thompson, R. R. Tykwinski, H. L. Anderson, J. Am. Chem. Soc. 2016, 138, 1366-1376, b) L. D. Movsisyan, D. V. Kondratuk, M. Franz, A. L. Thompson, R. R. Tykwinski, H. L. Anderson, Org. Lett. 2012, 14, 3424-3426; c) N. 
Weisbach, Z. Baranova, S. Gauthier, J. H. Reibenspies, J. A. Gladysz, Chem. Commun. 2012, 48, 7562-7564.

[8] S. L. Woltering, P. Gawel, K. E. Christensen, A. L. Thompson, H. L. Anderson, J. Am. Chem. Soc. 2020, 142, 13523-13532.

[9] S. Schrettl, E. Contal, T. Hoheisel, M. Fritzsche, S. Balog, R. Szilluweit, H. Frauenrath, Chem. Sci. 2015, 6, 564-574.

[10] J. Stahl, J. C. Bohling, E. B. Bauer, T. B. Peters, W. Mohr, J. M. MartínAlvarez, F. Hampel, J. A. Gladysz, Angew. Chem. Int. Ed. 2002, 41 1871-1876; Angew. Chem. 2002, 114, 1951-1957.

[11] a) C. Zhao, R. Kitaura, H. Hara, S. Irle, H. Shinohara, J. Phys. Chem. C 2011, 115, 13166-13170; b) L. Shi, P. Rohringer, K. Suenaga, Y. Niimi, J. Kotakoski, J. C. Meyer, H. Peterlik, M. Wanko, S. Cahangirov, A Rubio, Z. J. Lapin, L. Novotny, P. Ayala, T. Pichler, Nat. Mater. 2016 15, 634-640.

[12] S. Saito, E. Takahashi, K. Nakazono, Org. Lett. 2006, 8, 5133-5136.

[13] J. Berná, J. D. Crowley, S. M. Goldup, K. D. Hänni, A.-L. Lee, D. A. Leigh, Angew. Chem. Int. Ed. 2007, 46, 5709-5713; Angew. Chem. 2007, 119, 5811-5815.

[14] a) Y. Tobe, T. Fujii, K. Naemura, J. Org. Chem 1994, 59, 1236-1237; b) Y. Tobe, T. Fujii, H. Matsumoto, K. Naemura, Y. Achiba, T. Wakabayashi, J. Am. Chem. Soc. 1996, 118, 2758-2759.

[15] Y. Tobe, R. Umeda, N. Iwasa, M. Sonoda, Chem. Eur. J. 2003, 9, 5549-5559.

[16] D. C. Zecher, R. West, J. Am. Chem. Soc. 1967, 89, 153-155.

[17] a) Y. Rubin, F. Diederich, J. Am. Chem. Soc. 1989, 111, 6870-6871; b) Y. Rubin, C. B. Knobler, F. Diederich, J. Am. Chem. Soc. 1990, 112, 1607-1617; c) Y. Rubin, M. Kahr, C. B. Knobler, F. Diederich, C. L. Wilkins, J. Am. Chem. Soc. 1991, 113, 495-500; d) F. Diederich, Y Rubin, C. B. Knobler, R. L. Whetten, K. E. Schriver, K. N. Houk, Y. Li Science. 1989, 245, 1088-1090.

[18] a) Y. Rubin, C. B. Knobler, F. Diederich, J. Am. Chem. Soc. 1990, 112, 4966-4968; b) J. Lewis, B. Lin, M. S. Khan, M. R. A. Al-Mandhary, P. R. Raithby, J. Organomet. Chem. 1994, 484, 161-167; c) M. M. Haley, B. L. Langsdorf, Chem. Commun. 1997, 1121-1122.
[19] G. A. Adamson, C. W. Rees, J. Chem. Soc., Perkin Trans. 11996 1535-1543

[20] a) S. Eisler, R. R. Tykwinski, J. Am. Chem. Soc. 2000, 122, 1073610737; b) T. Luu, Y. Morisaki, N. Cunningham, R. R. Tykwinski, J. Org Chem. 2007, 72, 9622-9629.

[21] D. R. Kohn, P. Gawel, Y. Xiong, K. E. Christensen, H. L. Anderson, J. Org. Chem. 2018, 83, 2077-2086.

[22] N. Pavliček, P. Gawel, D. R. Kohn, Z. Majzik, Y. Xiong, G. Meyer, H. L. Anderson, L. Gross, Nat. Chem. 2018, 10, 853-858.

[23] a) K. Kaiser, L. M. Scriven, F. Schulz, P. Gawel, L. Gross, H. L. Anderson, Science 2019, 365, 1299-1301; b) L. M. Scriven, K. Kaiser, F. Schulz, A. J. Sterling, S. L. Woltering, P. Gawel, K. E. Christensen, H. L. Anderson, L. Gross, J. Am. Chem. Soc. 2020, 142, 12921-12924.

[24] a) G. Gil-Ramírez, D. A. Leigh, A. J. Stephens, Angew. Chem. Int. Ed. 2015, 54, 6110-6150; Angew. Chem. 2015, 127, 6208-6249; b) S. Mena-Hernando, E. M. Pérez, Chem. Soc. Rev. 2019, 48, 5016-5032.

[25] D. J. Cram, M. E. Tanner, R. Thomas, Angew. Chem. Int. Ed. 1991, 30, 1024-1027; Angew. Chem. 1991, 103, 1048-1054.

[26] M. J. Frampton, H. L. Anderson, Angew. Chem. Int. Ed. 2007, 46, 1028-1064; Angew. Chem. 2007, 119, 1046-1083.

[27] A. M. Blanco-Rodríguez, M. Towrie, J.-P. Collin, S. Záliš, A. Vlček, Jr., Dalton Trans. 2009, 3941-3949.

[28] M. Melmer, H. Neudeck, Monatsh. Chem. 1996, 127, 275-290.

[29] E. Vogel, W. Wiedemann, H. D. Roth, J. Eimer, H. Günther, Justus Liebigs Ann. Chem. 1972, 759, 1-36.

[30] A. H. Alberts, H. Wynberg, Chem. Commun. 1988, 748-749.

[31] P. Bönzli, M. Neuenschwander, Helv. Chim. Acta 1991, 74, 255-274.

[32] D. Boyall, F. López, H. Sasaki, D. Frantz, E. M. Carreira, Org. Lett. 2000, 2, 4233-4236.

[33] H. Lahlali, K. Jobe, M. Watkinson, S. M. Goldup, Angew. Chem. Int. Ed. 2011, 50, 4151-4155; Angew. Chem. 2011, 123, 4237-4241.

[34] Y. Tobe, N. Iwasa, R. Umeda, M. Sonoda, Tetrahedron Lett. 2001, 42, 5485-5488 


\section{Entry for the Table of Contents}



Text for Table of Contents: Active metal template synthesis has been used to prepare a [2]rotaxane in which the whole dumbbell component is a masked $\mathrm{C}_{16} \mathrm{H}_{2}$ polyyne. $t$-Butyl substituents make the photo-labile terminal groups bulky enough to act as stoppers and prevent unthreading of the macrocycle. Rotaxanes of this type are promising intermediates in the synthesis of mechanically interlocked carbon-rich architectures, such as cyclocarbons catenanes and carbyne polyrotaxanes.

Institute and/or researcher Twitter usernames: @HLAGroupOx 